\title{
Leader fields due to a lightning channel with an inclined upper section
}

\author{
C. Gomes ${ }^{1, *}$ and V. Cooray ${ }^{2}$ \\ ${ }^{1}$ Department of Physics, University of Colombo, Sri Lanka \\ 2 Institute of High Voltage Research, Uppsala University, Sweden
}

\begin{abstract}
It is shown theoretically the dependence of the leader field on the angle of orientation with respect to a perfectly conducting horizontal plane of the uppermost part of the lightning leader. The results were able to discern significantly large differences in the static field variation of leader channels with the same length but a certain channel segment is oriented at different angles. The outcome of our calculations consistently explains the scatter of the total leader field observed in previous studies. Otherwise, one has to assume unrealistic charge source heights or unreasonable charge densities to calculate matching values for some of the total leader fields and total leader field to return stroke filed ratios, labeled as anomalous observations in the literature. In some cases, irrespective of the charge source height and the charge density, one cannot find a suitable fit with the straight channel model.
\end{abstract}

\section{INTRODUCTION}

The static leader fields have been studied previously in [1] to [13]. A comprehensive review of the leader fields has been given in [10] and [11]. The terminology used to describe observations is not always without ambiguity. One possible confusion is the beginning of the stepped leader field variation. This is sometimes ambiguous due to the so-called preliminary breakdown event, which is said to occur prior to the initiation of the leader. The duration of the preliminary variation is also not clearly defined. As discussed in [11], the initial field change that ultimately end-up in a ground flash, is strongly related to the in-cloud discharges termed "cloud-type initial

\footnotetext{
${ }^{*}$ Corresponding author
} 
portion of the first leader field change” [14], "pre-preliminary discharge” [15], "long duration preliminary field change" [8], and "large negative pre-stroke field changes" outside the polarity reversal distance [9]. As we will discuss later, recent studies [16] have revealed that prior to stepped and dart leaders, there are several breakdown channels form in the cloud, which are not physically connected to the consequent path of the ground-directed leader.

It is an advantage for the work presented in this paper to state briefly the observations given in [11], which is probably the most detailed study in this regard. Their observations are based on simultaneous single station electric field and multiple station TV records of 3 convective thunderstorms occurred in Florida. They have analysed 286 strokes in 73 flashes for the leader field wave shapes. The approximate range of distance to the lightning from the measuring site has been given as 2.5 - 20.5 $\mathrm{km}$. They classified the observed leader field wave shapes into 3 broad categories. (1) A net negative hook shape electric field change. (2) A net positive or zero hook shaped electric field change. (3) A monotonic positive electric field change. They have also given examples of several cases where the leader field change is double-hooked shaped or oscillating. In the case of a number of subsequent leaders, the waveforms show a flattening (an inactive region) few milliseconds prior to the return stroke. They have given the histograms of each type of the leader fields (3 types categorised above), with respect to distance of observation from the channel base. They have also classified the histograms by the stroke order. The first category of leader fields tend to occur at smaller distances, while the second and third categories of leader fields are observed in flashes struck further away from the place of observation. The distribution of the first category of fields tends to shift to larger distances with increasing stroke order.

Krehbiel et al [8] have observed, that three negative stepped leaders out of four that they have detected, developed horizontally in the cloud before producing a vertical extension towards ground. They have done their experiment in New Mexico, with exposed circular plate antennas at eight locations beneath the thunderstorm to obtain electrostatic field change measurements, and with the aid of $3 \mathrm{~cm}$ radar measurements of precipitation structure of the storm. In the single flash analysed by [17], the discharge has started with several horizontal channels developed inside the cloud, one of which culminated in the development of a negative leader to ground and a return stroke. Their observation is based on VHF/interferometric technique. This horizontal propagation of one or several discharge channels, before that or one of them diverting vertically towards ground, has been clearly observed in several other studies conducted in the same geographical location (e.g. 4 flashes in [16] and 2 flashes in [18]). Using a radio interferometric technique, [19] have observed that the intracloud part of the lightning leaders is predominantly horizontal. Proctor [20], who recorded 26 radio images of lightning flashes, reported that many of those flashes have traveled horizontally inside the cloud before they went down vertically to ground. The observation of this inclined 
channel part inside the cloud is not a feature of only negative return strokes. Fuquay [21] has photographed several positive lightning channels, which have extensively long horizontal paths inside the cloud. In some cases, these horizontal channel segments were longer than the corresponding vertical section beneath the cloud.

Most of the research on leader fields are based on lightning measurements while in some cases a simple leader model (a line charge that extends downwards from a spherical symmetric charge or point charge in the cloud) is adapted to explain some observations. In most of the studies, where the observed leader fields are attempted to be reproduced by a simple leader model, several exceptional or anomalous cases were found [8].

The above mentioned observations and the drawbacks of the straight channel model lead us to investigate the leader fields due to channels with inclined upper sections. The ratio between the total leader field change and the total return stroke field change has been investigated for few azimuth angles in [11]. In [13] the above ratio as well as the total leader field change has been studied in detail for several elevation angles. In this study we investigate the time dependent leader field for different elevation angles. The atmospheric science sign convention is adapted in all the calculations of this work (i.e. negative polarity is assigned to the field change due to the raising of negative charge away from earth).

We theoretically show the dependence of the leader field (henceforth referred as LF), on the angle of orientation with respect to a perfectly conducting horizontal plane (henceforth referred as $\theta$ ) of the uppermost part of the lightning leader (henceforth referred as the oriented part), the length of which is denoted by $L$. The beginning of the leader proper is selected as the initiation of the movement of the charge from its original source location. This is the only feasible choice we have, as the observation on leader phase is somewhat ambiguous (as discussed earlier). The stepped leader and the dart leader will not be discriminated in this study as the recent observations on in-cloud electric activity, prior to ground strokes, have revealed that in both cases the channel may be inclined at the upper portion. As our main concern is to illustrate the dependence of LF on $\theta$, but not to give precise values, we adhered only to 2-D analysis. However, with time and effort, one can develop a computer algorithm to compute the leader and return stroke fields when the oriented part is at any direction of a 3-D hemispherical structure.

Mathematically, it is convenient to assume a uniform charge distribution along the channel in calculating leader fields [22]. However, one can expect a higher charge density towards the lower tip of the leader channel as the enhancement of the capacitance of the leader, in the vicinity of the ground, drains more charge towards this region. In many of the leader and return stroke models the leader charge distribution assumed is either exponential or linear. Larson and Cooray [23] discussed the physical validity of several leader charge distributions. In the present study, we considered a uniform charge distribution, solely due to the ease of mathematics. 


\section{THEORY}

The channel geometry considered for the calculation of field changes in this study is illustrated in Fig. 1. The leader field variation at distance $D$ at time t, due to a channel extending at speed $v$, is given by equation 1

$$
\begin{aligned}
& \mathrm{E}(\mathrm{t})=\frac{-2 \rho}{4 \pi \varepsilon_{0}} \int_{0}^{\mathrm{vt}} \frac{(\mathrm{Y}-\mathrm{v} \tau \sin \theta) \mathrm{d}(\mathrm{v} \tau)}{\left\{(\mathrm{Y}-\mathrm{v} \tau \sin \theta)^{2}+(\mathrm{X}+\mathrm{v} \tau \cos \theta) 2\right\}^{3 / 2}}-\mathrm{vt} \frac{\mathrm{Y}}{\left(\mathrm{Y}^{2}+\mathrm{X}^{2}\right)^{3 / 2}} \quad \text { for } \mathrm{vt} \leq \mathrm{L} \\
& \mathrm{E}(\mathrm{t})=\mathrm{E}(L / \mathrm{v})+\frac{-2 \rho}{4 \pi \varepsilon_{0}}\left[\frac{1}{\left\{\mathrm{D}^{2}+(\mathrm{H}-\mathrm{vt}+\mathrm{L})^{2}\right\}^{1 / 2}}\left\{\frac{1}{\left.\left\{\mathrm{D}^{2}+\mathrm{H}^{2}\right\}^{1 / 2}-(\mathrm{vt}-\mathrm{L}) \frac{\mathrm{Y}}{\left(\mathrm{Y}^{2}+\mathrm{X}^{2}\right)^{3 / 2}}\right] \quad \text { for } v t>L}\right\}\right.
\end{aligned}
$$

where $X=D-L \cos \theta$ and $Y=H+L \sin \theta$. Note that $l=v t, \quad d l=d(v \tau)$ and $\tan \alpha=$ $(X+v t \cos \theta) /(Y-v t \sin \theta)$

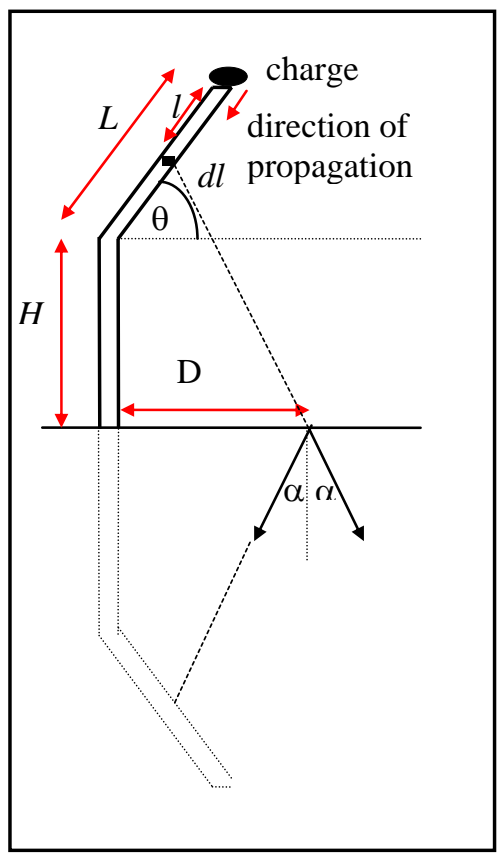

Fig. 1. Model of the leader channel used for calculations

In the calculation of leader fields $H, L$ and $\rho$ were given constant values of $5 \mathrm{~km}$, $3 \mathrm{~km}$ and $0.001 \mathrm{C} / \mathrm{m}$ respectively. $\theta$ was given the values of $0^{\circ}, 90^{\circ}$ and $180^{\circ}$. The leader speed was assumed to be $10^{5} \mathrm{~m} / \mathrm{s}$. 


\section{RESULTS}

Fig. 2 shows the leader field variation at several distances for a channel with a straight section $(H)$ of $5 \mathrm{~km}$ and an inclined part $(L)$ of $3 \mathrm{~km}$. Curve 1,2 and 3 correspond to $\theta$ values of $0^{\circ} 90^{\circ}$ and $180^{\circ}$ respectively. At very close distances (say $50 \mathrm{~m}$ ) the channel inclination has no significance in the field variation. In the case that the upper part of the channel is oriented towards the observer, one may observe field variations with no negative excursion, even at close distance (e.g. curve 1 at $3 \mathrm{~km}$ ). On the other hand, when the oriented part is inclined away from the observer a negative excursion can be seen in the field variation even at relatively large distances (e.g. curve 3 at $20 \mathrm{~km}$ ). At near range (say less than $5 \mathrm{~km}$ ) a channel with oriented part inclined away from the observer generates field variations somewhat similar to those due to straight channels. At far range (say greater than $10 \mathrm{~km}$ ) this similarity is seen between the fields due to channels with oriented part inclined towards the observer and that due to straight channels.

Fig. 3 compares the variation of leader fields, at $5 \mathrm{~km}$, due to a straight channel and a channel with inclined upper part. Curve 1 corresponds to a vertical channel with height $2 \mathrm{~km}$ while curve 2 is pertinent to a channel with $H, L$ and $\theta$ equal to $5 \mathrm{~km}, 3 \mathrm{~km}$ and $0^{\circ}$ respectively (during the first $20 \mathrm{~ms}$ ). Fig. 4 depicts a similar comparison, but in this case curve 1 corresponds to a leader channel with $10-\mathrm{km}$ height and curve 2 is associated with a channel of $H, L$ and $\theta$ equal to $5 \mathrm{~km}, 3 \mathrm{~km}$ and $180^{\circ}$ respectively. The time scale of curve 2 is multiplied by a factor of 0.8 to view a better comparison.

\section{DISCUSSION}

The field variations given in fig. 2 explain the reason for the observation of a number of cases anomalous to the representative curves of leader fields at different distances as given in the literature [1], [7], and [10].

It is of interest to investigate the discussion made by [10] on several of the previous observations. One such case is the observation of leader fields with no negative excursion at close distance (3-5 km). Beasley et al. [10] explained this observation as due to a channel about $10 \mathrm{~km}$. However, this field variation is not possible to be reproduced by the straight channel model, at this distance. Although, the reasoning of [10] cannot be ruled out, these calculations show that, though it is less probable, it is not impossible to observe such fields at close distance. With a proper combination of $H, L$ and $\theta$ one may reproduce LFs very similar to those observed by [1]. The other type of fields, as described in the above publication, has an initial slow variation, followed by a steady part to the return stroke, with a short slow increase, sometimes just before the return stroke. This observation fits into the LF observed at $3 \mathrm{~km}$ due to a channel with $\theta$ equals $0^{\circ}$ (fig. 2). 

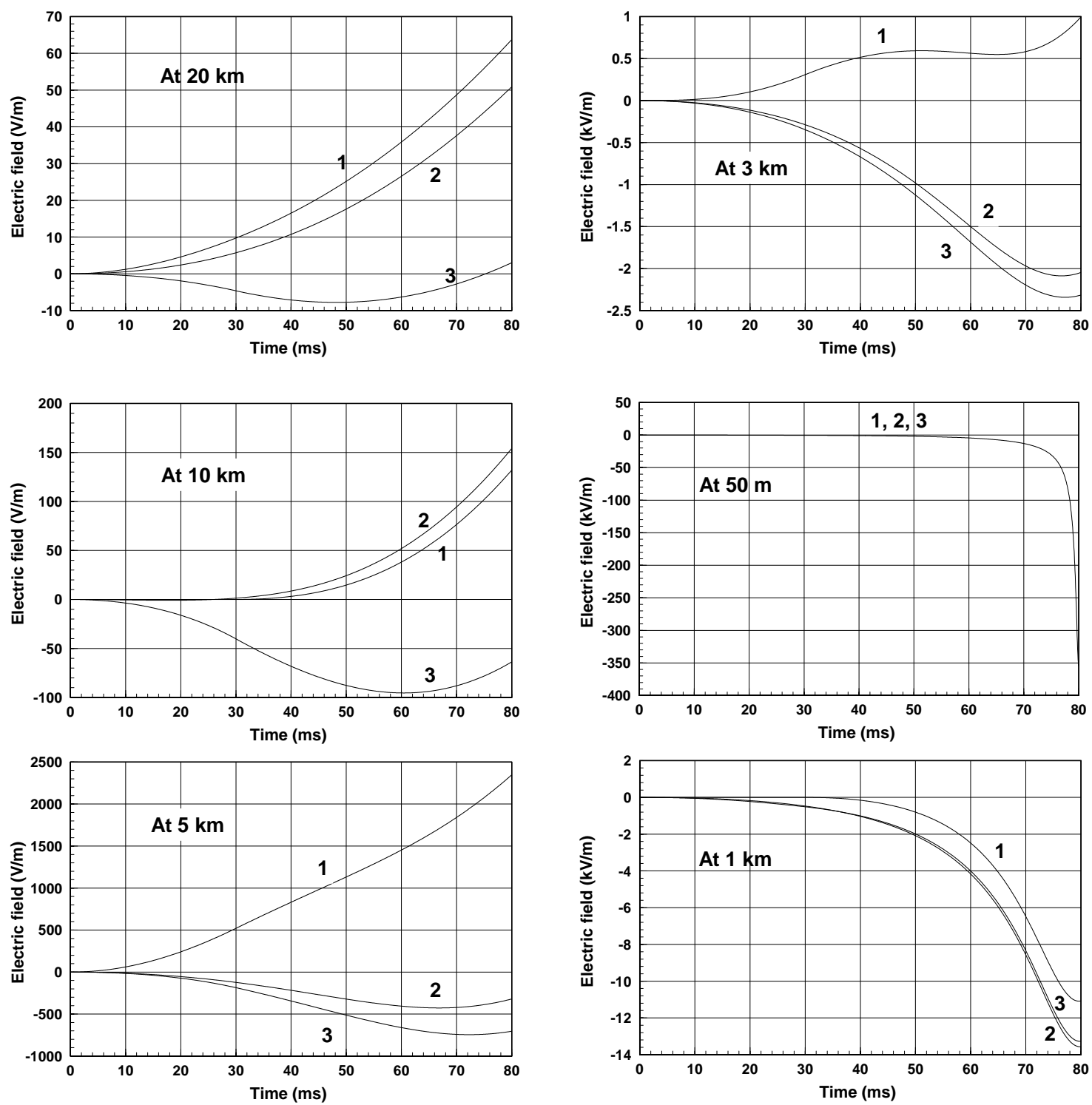

Fig. 2. Leader field variation at several distances for a channel with a straight section $(H)$ of $5 \mathrm{~km}$ and an inclined part $(L)$ of $3 \mathrm{~km}$ 
Another unusual (in the sense that not reported in other studies) leader field change has been given in [2], which they label as due to a so-called $\beta$ type leader (figure 4 of [2]). The field has an initial rise, which reaches a peak and gradually decreases to zero, followed by a short increase before the return stroke. Beasley et al. [10], suggested that this field variation is a result of a possible inaccuracy of the field observing technique. After several trials, we produced a similar field variation at $2.7 \mathrm{~km}$ for a channel with $H, L$ and $\theta$ equal $5 \mathrm{~km}, 3 \mathrm{~km}$ and $0^{\circ}$ respectively (fig. 5). It might be possible to produce an even better fit for the observed field with a more suited combination of $H, L, D$ and $\theta$. Thus, in this case too, although we do not totally discard the argument of [10], we may say that there is a certain probability, though it is slim, to observe such field variations.

This investigation shows also that the different types of leader field shapes as reported by [11] can be reproduced by channels with inclined parts. Specially, within 2-8 km, by choosing a proper combination of realistic values for $H, L$, and $\theta$, at a given distance one can calculate a leader waveform with a negative hook-shape, a positive hook-shape, a negative/positive excursion and then flattened shape, a monotonically increasing/decreasing shape, or even a double hook-shape (e.g. one can obtain a double hook-shape when $L$ of the leader channel in fig. 5 is increased while keeping other parameters the same). The fact that the higher order strokes at larger distances show leader fields with negative hook-shapes indicates that they have long horizontal parts inside the cloud.

In cases where the charge source height is determined by slow field measurements at ground, the estimation has a scatter within a broad range, for the same thunderstorm, if the sample size is large. For examples, [24]: 2.5-8.7 km amsl (above mean sea level) for 10 flashes; [25]: 6.0-9.5 km amsl for 70 flashes; [10]: 6.3-7.8 km amsl for 4 flashes; [26]: 5.2-9.3 km amsl for 26 flashes. The clear air temperature assigned to the source height, in turn, shows a large variation, which is unrealistic for the same thunderstorm. In contrast, when the same parameter is determined by VHF mapping, Radar pictures or balloon-borne measurements, this range was rather narrow. For examples, [20] radar pictures: 3.1-5.1 km above ground level for 26 flashes; [27] VHF mapping: group 1, 4.4-5.7 km amsl for 431 flashes and group 2, 7.5-9.7 km amsl for 337 flashes; [28] balloonborn instruments: 4.8-5.8 amsl.

The results of this study extensively account for the above contradiction in inferred information on charge source height. For one example, in the case of LF, the profile of the field due to a channel with $H, L$ and $\theta$ equal $5 \mathrm{~km}, 3 \mathrm{~km}$ and $0^{\circ}$ respectively, is similar to that of a straight channel with 2-km height (fig. 3). Thus, one may estimate the charge source height by observing the LF due to the leader channel with the inclined part, as $2 \mathrm{~km}$ (assuming a straight channel model), whereas the actual height is more than twice this estimation $(5 \mathrm{~km})$. As it is shown in Fig. 4 when the oriented part of the same channel is inclined horizontally away from the observer $\left(180^{\circ}\right)$, the field variation matches that due to a straight channel with $10 \mathrm{~km}$ height. Thus, the estimation of the charge source height, by straight channel model, will give a value two times greater. 


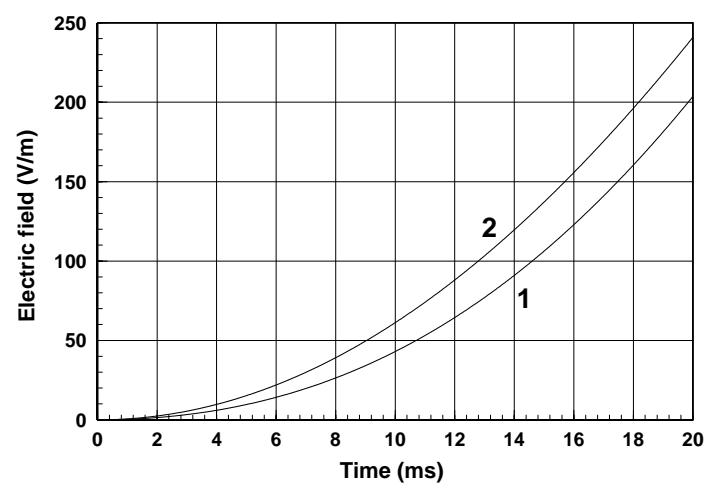

Fig. 3 The variation of leader fields, at $5 \mathrm{~km}$, due to a straight channel and a channel with inclined upper part. Curve 1 corresponds to a vertical channel with height $2 \mathrm{~km}$ while curve 2 is pertinent to a channel with $H, L$ and $\theta$ equal to $5 \mathrm{~km}, 3 \mathrm{~km}$ and $0^{\circ}$ respectively (during the first $20 \mathrm{~ms}$ ).

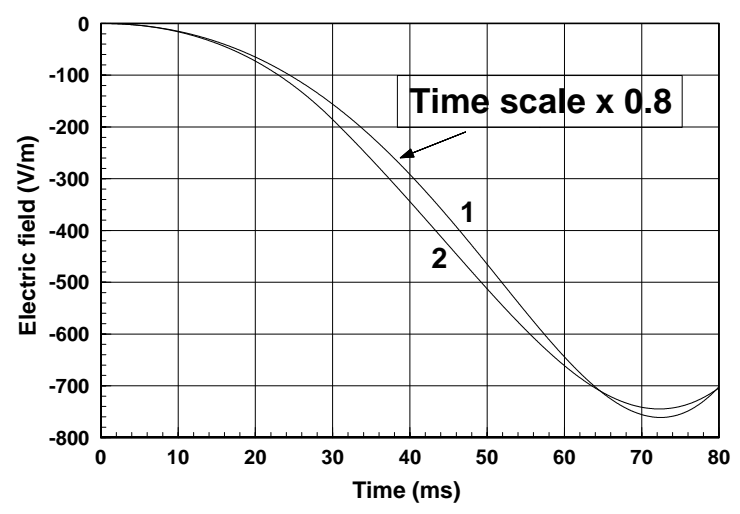

Fig. 4 The variation of leader fields, at $5 \mathrm{~km}$ Curve 1 corresponds to a leader channel with 10-km height and curve 2 is associated with a channel of $H, L$ and $\theta$ equal to $5 \mathrm{~km}, 3 \mathrm{~km}$ and $180^{\circ}$ respectively. The time scale of curve 2 is multiplied by a factor of 0.8 to view a better comparison.

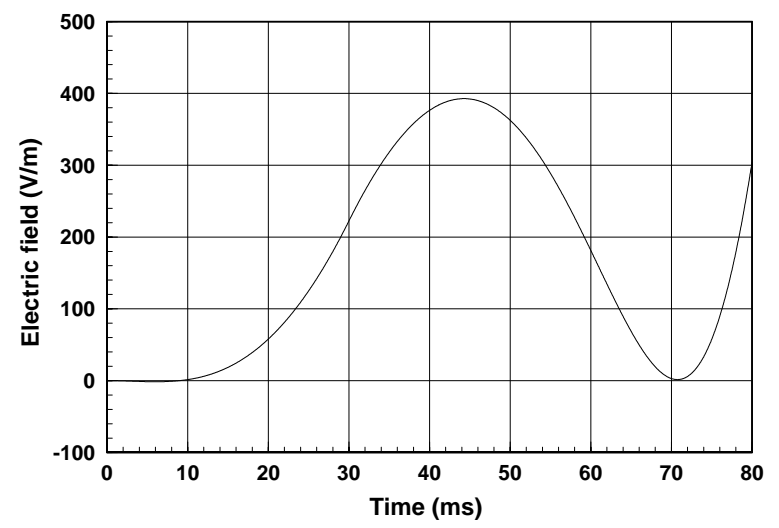

Fig. 5 Field variation at $2.7 \mathrm{~km}$ for a channel with $H, L$ and $\theta$ equal $5 \mathrm{~km}, 3 \mathrm{~km}$ and $0^{\circ}$ respectively. 


\section{CONCLUSIONS}

The objective of this chapter is to illustrate the variation of the leader field, at a certain distance, with the angle of inclination of a segment of the upper portion of the leader channel. We were able to discern significantly large differences in the static field variation of leader channels with the same length but a certain channel segment is oriented at different angles.

The outcome of our calculations consistently explains the scatter of the total leader field observed in previous studies. Otherwise, one has to assume unrealistic charge source heights or unreasonable charge densities to calculate matching values for some of the total leader fields and total leader field to return stroke filed ratios, labeled as anomalous observations in the literature. In some cases, irrespective of the charge source height and the charge density, one cannot find a suitable fit with the straight channel model.

With highly developed interferometric techniques available at present for mapping electric activity inside thunderclouds, one can further evaluated the variation in LF with channel orientations that has been considered in this study. However, one may need to generalise these calculations for 3$\mathrm{D}$ rotation of the oriented part of the channel prior to these results being employed in deducing related lightning parameters.

\section{REFERENCE}

1 Appleton, E. V., and F. W. Chapman, On the nature of Atmospherics, 4, Proc. Roy. Soc. London, ser. A, 158, 1-22, 1937

2 Schonland B. J. F., D. B. Hodges, and H. Collens; Progressive lightning-5, A comparison of photographic and electrical studies of the discharge, Proc. Roy. Soc. London, A, 166, 56-75, 1938

3 Chapman, F. W., Atmospheric disturbances due to thundercloud discharges, 1, Proc. Roy. Soc. London, ser. A, 51, 876-894, 1939

4 Malan, D. J., Les descharges dans l'air et la charge inferieure positive d'un nuage orageux, Ann. Geophys., 8, 385-401, 1952

5 Pierce, E. T., Electrostatic field changes due to lightning discharges, Q. J. Roy. Meteorol. Soc., 81, 211-228, 1955

6 Kitagawa, N., On the electric change due to the leader processes and some of their discharge mechanism, Pap. Meteorol. Geophys., Tokyo, 7, 400-414, 1957

7 Clarence N. D., and D. J. Malan, Preliminary discharge processes in lightning flashes to ground, Q. J. Roy. Meteorol. Soc., 83, 161-172, 1957

8 Krehbiel, P. R., M. Brook, and R. McCroy, An analysis of the charge structure of lightning discharges to ground, $J$. Geophys. Res., 84, 2432-2456, 1979

9 Thomson, E. M., Characteristics of Port Morseby ground flashes, J. Geophys. Res., 85, 1027-1036, 1980

10 Beasley, W. H., M. A. Uman, and P. Rustan, Electric fields preceding cloud-to-ground lightning flashes, J. Geophys. Res., 87, 4883-4902, 1982

11 Rakov, V. A. and M. A. Uman, Waveforms of first and subsequent leaders in negative lightning flashes, Journal of Geophysical Research, 95, 16,561-16,577, 1990

12 Rakov, A. V., M. A. Uman, D. M. Jordan, and C. A. Priore, ratio of return stroke electric field change for first and subsequent lightning strokes, J. Geophys. Res., 95, 16579-16587, 1990

13 Gomes C. and V. Cooray, The dependence of the total leader return stroke field changes on the orientation of a segment of the leader channel, 13th International Symposium on EMC, Zurich, Switzerland, 106P2, 1999 
14 Kitagawa, N., and M. Brook, A comparison of intracloud and cloud to ground lightning discharge, Journal of Geophysical Research, 65, 1189-1201, 1960

15 Ishikawa, H., Nature of lightning discharges as origins of atmospherics, Proceedings of the Research Institute of Atmospherics, Nagoya University, 8A, 1-273, 1961

16 Shao, X. M., The development and structure of lightning discharges observed by VHF radio interferometry, Ph.D. Thesis, University of Florida, USA, 1993

17 Rhodes, C. T., and P. R. Krehbiel, Interferometric observations of a single cloud-to-ground flash, Geophys. Res. Lett., 16, 1169-1172, 1989

18 Rhodes, C. T., X. M. Shao, P. R. Krehbiel, R. J. Thomas, and C. O. Hayenga, Observations of lightning phenomena using radio interferometry, J. Geophys. Res., 99, 13059-13082, 1994.

19 Hayenga C. O., and J. W. Warwick, Two-dimensional interferometric positions of VHF lightning sources, J. Geophys. Res., 86, 7451-7462, 1981

20 Proctor, D. E., VHF radio pictures of cloud flashes, J. Geophys. Res., 86, 4041-4071, 1981

21 Fuquay, D. M., Positive cloud to ground lightning in summer thunderstorms, J. Geophys. Res., 87, 7,131-7,140, 1982

22 Uman, M. A., Lightning, Dover Publications, NY, 1969

23 Larsson, A., and V. Corey, Charge distribution in the lightning leader channel, Proc. 23rd Int. Conf. on Lightning Protection, Florence, Italy, pp. 56-60, 1996

24 Barnard, V., The approximate mean height of the thundercloud charges taking part in a flash to ground, J. Geophys. Res., 56, 33-35, 1951

25 Jacobson, E. A., and E. P. Krider, Electrostatic field changes produced by Florida lightning, J. Atmos. Sci., 33, 103117, 1976

26 Krehbiel, P. R., An analysis of the electric field change produced by lightning, PhD thesis, Univ. Manchester Inst. Sci. Tech. UK, 1981

27 Proctor, D. E., Regions where lightning flashes began, J. Geophys. Res., 96, 5099-5112, 1991

28 Winn, W. P., C. B. Moore, and C. R. Holmes, Electric field structure in active part of a small, isolated thundercloud, J. Geophys. Res., 86, 1187-1193, 1981 